\title{
Infecção pulmonar por "Rhodococcus equi": relato dos dois primeiros casos brasileiros
}

\author{
Luiz CARlos SeVero ${ }^{1}$, Patricia RitTeR ${ }^{2}$, Victor FláVio PeTRILlO ${ }^{3}$, \\ Cícero ARMídio Gomes Dias ${ }^{4}$, Nelson da SILVA PorTO ${ }^{5}$
}

O Rhodococcus equi, principal agente da rodococose, é um cocobacilo pleomórfico, gram-positivo e aeróbio, que infecta humanos por via inalatória ou transcutânea e se manifesta clinicamente como abscesso pulmonar. Relatam-se os dois primeiros casos brasileiros da doença. Ambos os pacientes eram imunocomprometidos e apresentavam quadro infeccioso pulmonar. O primeiro tinha AIDS $e$ apresentava pneumonia cavitada em lobo superior esquerdo, que teve evolução fatal. O segundo tinha doença de Goodpasture, insuficiência renal crônica e fazia uso de corticosteróides. Apresentava uma lesão pulmonar escavada no lobo superior direito, que foi tratada com sulfametoxazol-trimetoprim, com resolução do processo. (J Pneumol 2001;27(3):158-162)

\section{Pulmonary Rhodococcus equi infection: report of the first two Brazilian cases}

Rhodococcus equi, the principal agent of rhodococcosis, is a pleomorphic, gram-positive, aerobic coccus bacillus that infects humans by inhalation or through a transcutaneous route. It is clinically manifested as a pulmonary abscess. The first two Brazilian cases of rhodococcosis are reported on. Both patients were immunocompromised and showed pulmonary infection. The first patient had AIDS and cavitating pneumonia in the left upper lobe, that was fatal. The second case presented Goodpasture syndrome and was under chronic corticotherapy. He displayed a cavitating nodular lesion in the right upper lobe, that was successfully treated with sulfametoxazol-trimethoprim.

Descritores - Infecções por actinomycetales. Tuberculose pulmonar. Síndrome de imunodeficiência adquirida. Síndrome de Goodpasture. Brasil.

Key words - Actinomycetal infections. Pulmonary tuberculosis. Acquired immunodeficiency syndrome. Goodpasture syndrome. Brazil.

\section{INTRODUÇÃO}

Rhodococcus equi (previamente Corynebacterium equi), principal agente da rodococose, é um cocobacilo pleomórfico, gram-positivo, aeróbio, parcialmente acidorresistente, não formador de esporos, imóvel, amplamen-
Siglas e abreviaturas utilizadas neste trabalho

AIDS - Síndrome da imunodeficiência adquirida CDC - Centers for Disease Control and Prevention ELISA - Imunoensaio enzimático HIV - Vírus da imunodeficiência humana CD4 - Linfócitos T-auxiliares
1. Instituto de Pesquisas e Diagnóstico (IPD), Santa Casa, Porto Alegre, RS; Pesquisador do CNPq.

2. Acadêmica de Medicina, UFRGS; Bolsista do CNPq.

3. Microbiologista Clínico (IPD).

4. Professor da Fundação Federal de Ciências Médicas de Porto Alegre. te distribuído na natureza. A infecção pode ser adquirida por via inalatória ou transcutânea ${ }^{(1)}$.

A rodococose, inicialmente descrita em veterinária(1), teve o primeiro relato em humanos, em 1967, em um
5. Médico Radiologista e Diretor do Pavilhão Pereira Filho, Santa Casa. Endereço para correspondência - Luiz Carlos Severo, IPD-Santa Casa, Annes Dias, 285 - 90020-090 - Porto Alegre, RS. Fax (51) 214-8435; E-mail: severo@santacasa.tche.br

Recebido para publicação em $8 / 8 / 00$. Aprovado, após revisão, em 20/9/00. 




Figura 1 - Caso 1: A radiografia de tórax (ago/89) evidencia grande cavidade necrótica $(10 \times 9 \mathrm{~cm})$ no lobo superior esquerdo, de paredes espessadas e irregulares com nível hidroaéreo.

paciente com abscesso pulmonar ${ }^{(2)}$. Contudo, nos últimos anos, tem sido descrito com freqüência crescente como pneumonia necrosante e abscesso pulmonar, em pacientes com alteração na imunidade celular, especialmente infectados pelo HIV $\mathrm{H}^{(3-5)}$.

$\mathrm{O}$ relato dos dois primeiros casos de rodococose pulmonar ocorridos em nosso meio justifica esta apresentação.

\section{RELATO DOS CASOS}

\section{Caso 1}

Homem branco de 33 anos, procedente de Porto Alegre, RS, etilista e tabagista desde os 15 anos de idade, anti-HIV (ELISA) positivo havia três anos, apresentava queixa de dor ventilatório-dependente em hemitórax esquerdo, tosse e expectoração purulenta, fétida e com raias de sangue. Referia náuseas, vômitos e diarréias ocasionais. $\mathrm{O}$ exame físico mostrou paciente emagrecido (perda de 15/ $58 \mathrm{~kg}$, em um mês), mucosas descoradas, temperatura axilar de $38^{\circ} \mathrm{C}$ e candidose oral. Ausculta pulmonar: diminuição do murmúrio vesicular no terço superior do hemitórax esquerdo. Radiografia de tórax evidenciou grande cavidade necrótica $(10 \times 9 \mathrm{~cm})$ no lobo superior esquerdo, de paredes espessadas e irregulares com nível hidroaéreo (Figura 1). O hemograma mostrava 8.600 leucócitos (17\% bastonetes, $72 \%$ segmentados, $6 \%$ monócitos, $5 \%$ linfócitos). Repetidas hemoculturas para bactérias foram negativas. Exame bacterioscópico do escarro mostrou cocos e bacilos gram-positivos; em cultivo cresceu Candida albicans e bactéria caracterizada como Corynebacterium

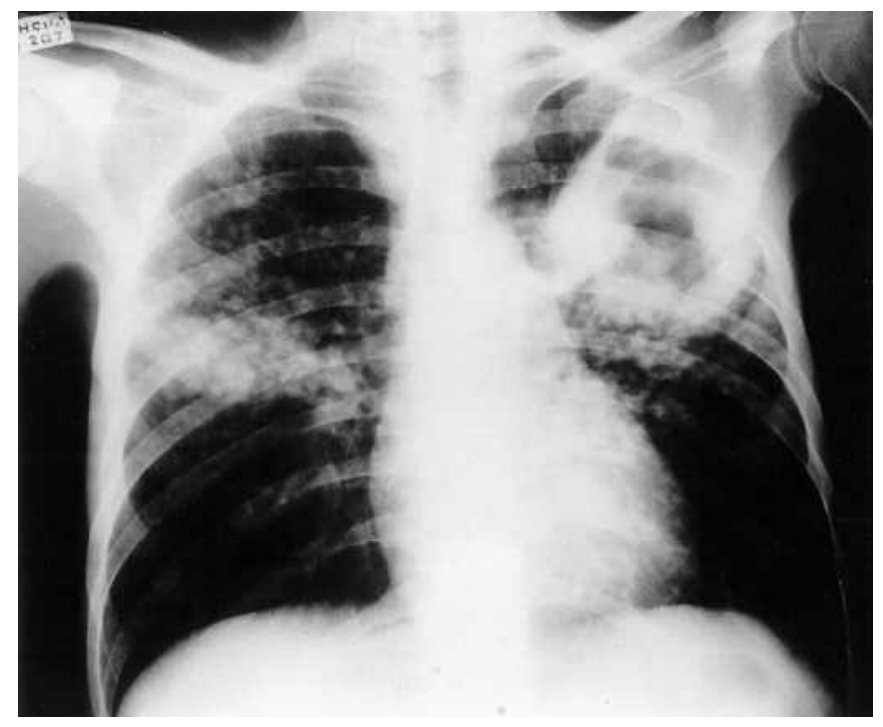

Figura 2 - Caso 1: Nova radiografia (out/89) mostrou aumento do infiltrado pulmonar nos segmentos anteriores dos lobos superiores e disseminação brônquica para o segmento superior do lobo inferior direito.

spp. Como não respondeu ao tratamento com penicilina e amicacina, foi feita uma fibrobroncoscopia. No lavado broncoalveolar observaram-se à microscopia, em esfregaços corados pela técnica de Kinyoun, cocobacilos acidorresistentes. Foi instituído tratamento tuberculostático (rifampicina, isoniazida e pirazinamida), sem melhora clínica. $\mathrm{O}$ paciente piorou clinicamente, acentuando-se a leucocitose e o desvio à esquerda. Radiografia de tórax, dois meses após a primeira, mostrou aumento do infiltrado pulmonar nos segmentos anteriores dos lobos superiores e disseminação brônquica para o segmento superior do lobo inferior direito (Figura 2). O paciente começou a apresentar encefalopatia hepática, leucopenia e plaquetopenia. Aumentaram os episódios de epistaxe e hemoptise, com grande perda sanguínea, acompanhada de perda de tecido fibronecrótico pela ruptura do abscesso pulmonar, evoluindo para o óbito dois meses depois de sua internação.

Autópsia - O pulmão direito pesava 980g e o esquerdo, 860g. Macroscopicamente, identificava-se área de cavitação com perda de substância em lobo inferior direito medindo cerca de $12 \mathrm{~cm}$ de diâmetro, de fundo granular, acinzentado e fosco, com aderências fibrinosas e material necro-hemorrágico. Ao corte observou-se, em correspondência a essa área, necrose circunjacente $e$, em ambos os pulmões, inúmeros nódulos amarelo-claros, opacos, firmes, por vezes granulares, e por vezes confluentes, ocupando cerca dos dois terços inferiores. O restante do parênquima mostrava edema alveolar e congestão. A microscopia dos pulmões evidenciava a presença de inú- 


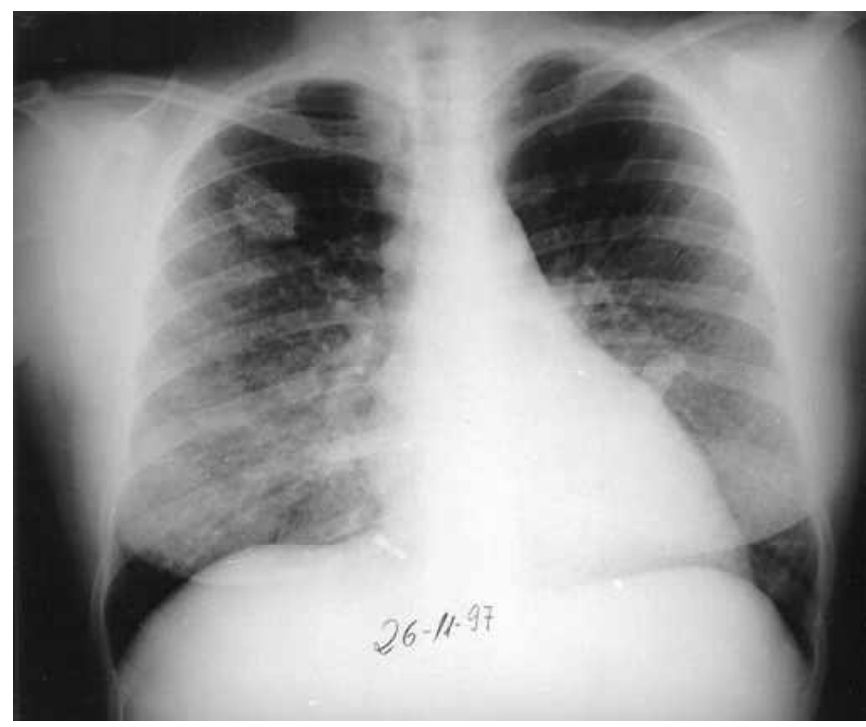

Figura 3 - Caso 2: Na radiografia de tórax (nov/97) observa-se lesão nodular escavada no lobo superior direito.

meros acúmulos de macrófagos com necrose central (granulomas com supuração central). Por vezes, as áreas de necrose eram confluentes. Havia ainda fibrose intersticial, edema alveolar e membranas hialinas recobrindo alvéolos e ductos. Os demais órgãos do bloco torácico, abdominais e cavidade craniana não mostraram alterações dignas de nota.

Na reavaliação dos cultivos tidos como Corynebacterium spp., levantou-se a hipótese de rodococose pela cor salmão das colônias. Repiques enviados ao CDC, Atlanta, EUA, tiveram a confirmação de Rhodococcus equi.

\section{Caso 2}

Mulher branca de 22 anos, procedente de Porto Alegre, anti-HIV (ELISA) negativo, portadora de doença de Goodpasture e insuficiência renal crônica havia quatro anos, quando iniciou hemodiálise. Havia dois meses recebendo prednisona $60 \mathrm{mg} /$ dia por apresentar anticorpos antimembrana basal. Hospitalizada com febre, tosse com escassa expectoração, episódios de escarro hemoptóico, mialgias, fadiga e sudorese noturna. Ao exame físico encontrava-se em bom estado geral, lúcida e com mucosas úmidas e coradas, anictérica, acianótica, taquipnéica, taquicárdica e temperatura axilar de $38,6^{\circ} \mathrm{C}$. Apresentava candidose oral. O hemograma mostrava 9.000 leucócitos (59\% segmentados, 33\% linfócitos, 3\% bastonetes, $1 \%$ eosinófilos). A radiografia de tórax evidenciou lesão nodular escavada no lobo superior direito (Figura 3). A punção pulmonar transcutânea aspirativa mostrou, nos esfregaços corados pelas técnicas de Kinyoun e Gram, cocobacilos gram-positivos, acidorresistentes; os cultivos permitiram a caracterização do $R$. equi por intermédio

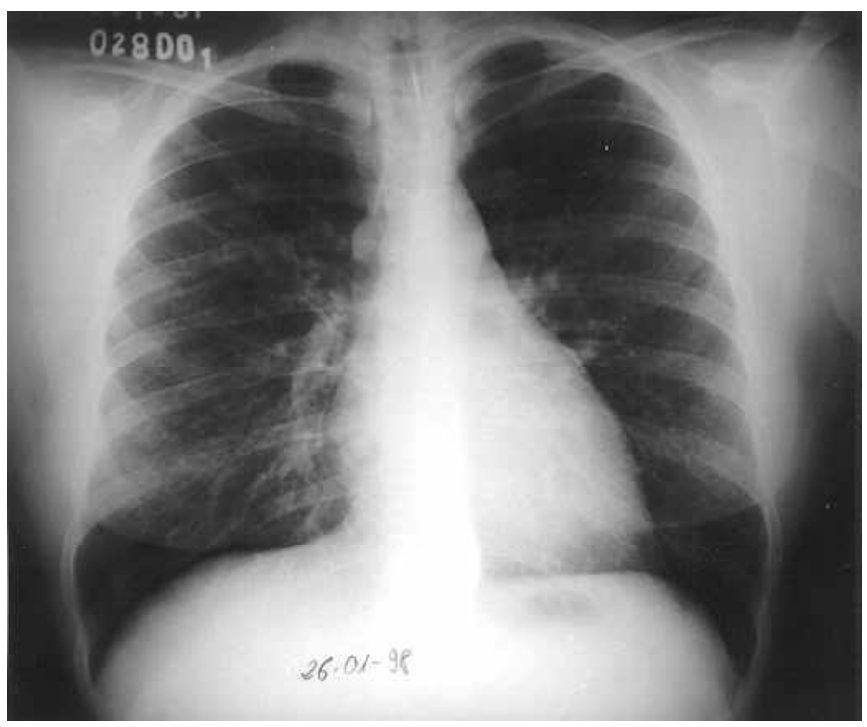

Figura 4 - Caso 2: Controle radiológico (jan/98), após término do tratamento, com regressão total da lesão.

de provas bioquímicas do sistema API Coryne ${ }^{\circledR}$ (BioMérieux AS, Marcy l'Etoile, France). A paciente foi tratada com sulfametoxazol-trimetoprim por um período de 30 dias. Realizou-se também retirada progressiva da prednisona. Após o término do tratamento, o controle radiológico, realizado 13 meses após a primeira radiografia, mostrou regressão total da lesão (Figura 4).

\section{DISCUSSÃO}

A alta prevalência da tuberculose em nosso meio faz com que infecções crônicas causadas por actinomicetos aeróbios (nocardiose, rodococose) não sejam reconhecidas clinicamente ou sejam diagnosticadas equivocadamente no laboratório, devido à acidorresistência em comum com as micobactérias.

Nesse sentido, a adequada colheita e processamento do espécime clínico é de fundamental importância para a confirmação etiológica. Embora o microrganismo possa ser identificado no escarro e lavado broncoalveolar (caso 1), a punção aspirativa transcutânea fornece material para um diagnóstico inequívoco (caso 2). A punção transcutânea aspirativa é o principal exame diagnóstico, pois é um método barato, bem tolerado pelos pacientes e de rápida execução e recuperação(6).

O R. equi é patógeno oportunista emergente $e^{(3)}$, especialmente em pacientes infectados pelo HIV (50\%), embora em $10 \%$ dos casos não tenha sido verificada causa aparente de imunodepressão(3,7). O predomínio no sexo masculino pode ser explicado em parte pela AIDS e pelo maior contato com animais( ${ }^{(7)}$. Nestes pacientes, a infecção pulmonar é a apresentação clínica mais comum. Pes- 
soas hígidas, quando infectadas, apresentam lesão extrapulmonar(7), como verificado anteriormente em nosso meio(8).

Os pacientes com acometimento pulmonar costumam apresentar mal-estar, fadiga, febre de aparecimento gradual, anorexia, emagrecimento, tosse produtiva, hemoptise, dispnéia e dor pleurítica ${ }^{(1,9)}$. As manifestações de disseminação extrapulmonares, fruto de bacteremia ${ }^{(10)}$, têm sido descritas como meningite $e^{(11)}$ e abscessos cutâneo, cerebral e ósseo ${ }^{(1)}$. Mais raramente, a lesão subcutânea pode ser infecção primária( ${ }^{(8,12)}$.

$\mathrm{Na}$ radiografia torácica observa-se inicialmente lesão infiltrativa, desde nódulos de $2 \mathrm{~cm}$ de diâmetro (caso 2) até uma lesão escavada ocupando todo o lobo pulmonar (caso 1). Em alguns casos observa-se lesão pseudotumoral pulmonar ${ }^{(13)}$, massa endobrônquica com abscesso pulmonar ${ }^{(14)}$ ou derrame pleural ${ }^{(1)}$. A lesão pulmonar quando não tratada pode mostrar nível hidroaéreo na cavidade (Figura 1), à semelhança da nocardiose $e^{(15)}$.

$\mathrm{O}$ aspecto anatomopatológico da lesão é pneumonia necrosante com abscesso. Usualmente, a reação é granulomatosa com substituição do parênquima pulmonar por camadas de histiócitos epitelióides com citoplasma granular a eosinofílico abundante, linfócitos e plasmócitos ${ }^{(16)}$. $\mathrm{O}$ aspecto micromorfológico e tintorial desse microrganismo é de cocobacilos gram-positivos agrupados, levemente acidorresistentes (Kinyoun) no interior de vários histiócitos. Acredita-se que o R. equi seja o agente causal de malacoplaquia, doença rara mais freqüente no trato urinário baixo, mas já descrita em vários outros órgãos, inclusive no pulmão(16,17).

$\mathrm{O} R$. equi cresce em meio de cultura aeróbio a $37^{\circ} \mathrm{C} e$ em 48 horas já mostra colônias esféricas irregulares, lisas, semitransparentes, brilhosas, mucóides, em forma de lágrima, com $2-4 \mathrm{~mm}$. Em quatro a seis dias apresentam cor salmão em meio não seletivo. O R. equi é cocobacilo gram-positivo fracamente acidorresistente, podendo ser confundido com difteróides; por isso é comum ser considerado uma contaminação e não valorizado em cultivo(9).

\section{REFERÊNCIAS}

1. Prescott JF. Rhodococcus equi: an animal and human pathogen. Clin Microbiol Rev 1991;4:20-34.

2. Goulub B, Falk G, Spink WW. Lung abscess due to Corynebacterium equi. Report of first human infection. Ann Intern Med 1967;66:1174-1177.

3. Scott MA, Graham BS, Verrall R, Dixon R, Schaffner W, Tham KT. Rhodococcus equi - An increasingly recognized opportunistic pathogen. Report of 12 cases and review of 65 cases in the literature. Clin Microbiol Infect Dis 1995;103:649-655.

4. Johnson DH, Cunha BA. Rhodococcus equi pneumonia. Semin Respir Infect 1997; 12:57-60.

5. Capdevila JA, Buján S, Gavalda J, Ferrer A, Pahissa A. Rhodococcus equi pneumonia in patients infected with the human immunodeficien-
No Brasil, fora o caso de infecção subcutânea referi$\mathrm{do}^{(8)}$, não encontramos registro de manifestação pulmonar da bacteriose. Contudo, é provável que um médico atento para o problema venha a fazer esse diagnóstico com mais freqüência, levando a tratamento precoce, com recuperação do paciente (caso 2).

$R$. equi deve entrar no diagnóstico diferencial de lesões pulmonares escavadas com micobacterioses e nocardiose $^{(18)}$ e laboratorialmente com microrganismos acidorresistentes ${ }^{(15)}$. Como entre as bactérias com essa característica somente $M$. tuberculosis é primariamente patogênico para o pulmão, tuberculose é o diagnóstico para o paciente imunocompetente. Contudo, pacientes imunocomprometidos, com esse mesmo achado, ainda que predomine $M$. tuberculosis como agente etiológico, é obrigatória a identificação através de cultivo de germes acidorresistentes. Nesse sentido, chama atenção a cor salmão das colônias do R. equi, obtidas em meios de cultivo da rotina de microbiologia clínica.

É importante o estudo da suscetibilidade aos antimicrobianos para o correto manejo dos pacientes ${ }^{(19)}$. O R. equi costuma responder a vários antimicrobianos, especialmente os lipofílicos, por penetrarem os macrófagos e neutrófilos onde está o microrganismo ${ }^{(1)}$. Uma sugestão terapêutica é a associação de vancomicina e eritromicina por dois meses pelo menos ${ }^{(9)}$. Além da antibioticoterapia, é indicada a ressecção cirúrgica de tecido necrótico, drenagem de lesões supurativas e controle de fatores predisponentes ${ }^{(1,9)}$.

Por fim, a infecção por $R$. equi deve ser suspeitada em todo paciente imunodeprimido ou HIV positivo com pneumonia lentamente evolutiva, especialmente em presença de necrose tecidual e em pacientes com CD4 entre 50 e 200 células $^{(20)}$.

\section{AgradeCimentos}

Os autores são gratos aos Drs. June M. Brown e Michael M. McNeil, Division of Bacterial \& Mycotic Diseases, Centers for Disease Control and Prevention (CDC), Atlanta, EUA, pela identificação da cepa do caso 1 .

cy virus. Report of two cases and review of the literature. Scand $\mathrm{J}$ Infect Dis 1997;29:535-541.

6. Falguera M, Nogues A, Ruiz-Gonzales A, Garcia M, Puig T, RubioCaballero M. Transthoracic needle aspiration in the study of pulmonary infections in patients with HIV. Chest 1994;106:697-702

7. Verville TD, Huycke MM, Greenfield RA, Fine DP, Kuhls TL, Slater LN. Rhodococcus equi infections of humans: 12 cases and a review of the literature. Medicine 1994;73:119-132.

8. Severo LC, Petrillo VF, Coutinho LMB. Actinomycetoma caused by Rhodococcus spp. Mycopathologia 1987;98:129-131.

9. Lasky JA, Pulkingham N, Powers MA, Durack DT. Rhodococcus equi causing human pulmonary infection: review of 29 cases. Southern Med J 1991;84:1217-1220. 
10. Sladek GG, Frame JN. Rhodococcus equi causing bacteremia in an adult with acute leukemia. Southern Med J 1993;86:244-246.

11. DeMarais PL, Kocka FE. Rhodococcus meningitis in an immunocompetent host. Clin Infect Dis 1995;20:167-169.

12. Adal KA, Shiner PT, Francis JB. Primary subcutaneous abscess caused by Rhodococcus equi. Ann Intern Med 1995;112:317.

13. Bishopric GA, d'Agay MF, Schlemmer B, Sarfati E, Brocheriou C Pulmonary pseudotumor due to Corynebacterium equi in a patient with the acquired immunodeficiency syndrome. Thorax 1988;43:486-487.

14. Shapiro JM, Romney BM, Weiden MD, White CS, O'Toole KM. Rhodococcus equi endobronchial mass with lung abscess in a patient with AIDS. Thorax 1992;47:62-63.

15. Petrillo VF, Severo LC, Londero AT, Porto NS. Pulmonary nocardiosis report of the first two Brazilian cases. Mycopathologia 1978;66:17-20.
16. Kwon KY, Colby TV. Rhodococcus equi pneumonia and pulmonary malakoplakia in acquired immunodeficiency syndrome. Pathologic features. Arch Pathol Lab Med 1994;118:744-748.

17. Peralta-Venturina MN, Clubb FJ, Kielhofner MA. Pulmonary malakoplakia associated with Rodococcus equi infection in a patient with acquired immunodeficiency syndrome. Am J Clin Pathol 1994;102: 459-463.

18. Gallant JE, Ko AH. Cavitary pulmonary lesions in patients infected with human immunodeficiency virus. Clin Infect Dis 1996;22:671-682.

19. McNeil MM, Brown JM. Distribution and antimicrobial susceptibility of Rhodococcus equi from clinical specimens. Eur J Epidemol 1992;8: 437-443.

20. Shah RM, Kaji AV, Ostrum BJ, Friedman AC. Interpretation of chest radiographs in AIDS patients: usefulness of CD4 lymphocyte counts. Radiographics 1997;17:47-62. 